
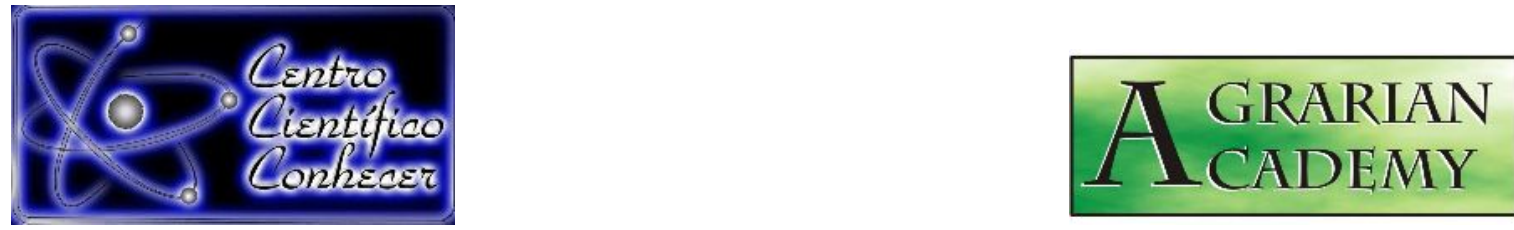

\title{
USO DE DIFERENTES CORANTES PARA A ESTIMATIVA DA VIABILIDADE POLÍNICA E CARACTERIZAÇÃO DOS GRÃOS DE POLENS DE SORGO GRANÍFERO
}

Talita Neres Queiroz ${ }^{1}$, Nayara Tayane da Silva ${ }^{1}$, Stephanie Mariel Alves ${ }^{1}$, Priscila Ninon do Nascimento ${ }^{1}$, Isane Vera Karsburg ${ }^{2}$

1- $\quad$ Mestranda em Genética e Melhoramento de Plantas pela Universidade do Estado de Mato Grosso (UNEMAT), Campus Alta Floresta- Mato Grosso, Brasil. talita.neres@gmail.com

2- $\quad$ Profa Adjunto da Universidade do Estado de Mato Grosso (UNEMAT).

Departamento de Ciências Biológicas e professora no Programa de Mestrado em Genética e Melhoramento de Plantas Campus de Alta Floresta - MT, Brasil.

Recebido em: 14/07/2018 - Aprovado em: 28/07/2018 - Publicado em: 31/07/2018

DOI: 10.18677/Agrarian_Academy_2018a32

Como a grande maioria das plantas cultivadas, a cultura do sorgo está sujeita a diferentes variações ambientais. Assim, a resposta fotoperiódica típica de dia curto e de altas taxas fotossintéticas, está relacionada a um bom crescimento, desenvolvimento, e germinação do pólen. O trabalho teve por objetivo estimar a viabilidade polínica, sob diferentes tipos de corantes e a caracterização do grão de pólen, quanto a sua viabilidade e tamanho. Foram analisadas 250 grãos de pólen/lâmina, com 30 repetições, em microscópio óptico modelo Primo Star Carl Zeiss., tendo imagens capturadas por meio de um microscópio fotômico binocular (Leica ICC 50) acoplado a um computador e no software LAZ EZ V1. 7.0, para caracterização quanto a sua morfologia de diâmetro equatorial (DE) e diâmetro polar (DP), pelo software ImageJ. As médias da viabilidade polínica foram submetidas à análise de variância (ANOVA), no software SISVARß, pelo teste Tukey à $5 \%$ de probabilidade. As análises de grãos de pólen do híbrido BRS 330, utilizando três diferentes corantes para estimar a viabilidade polínica, mostrou uma alta taxa de pólen viável, acima de $94 \%$, sendo que a orceína acética apresentou o maior percentual de pólens viáveis (96.24\%), seguido do Alexander (94.68\%) e por último o Lugol (94.04\%). A média para a relação diâmetro equatorial por diâmetro polar foi maior para os polens viáveis com valor de 0.94 , determinando assim a classificação do pólen em relação ao seu formato, sendo este oblato-esferoidal, já os grãos de pólen inviáveis apresentaram média de 0.80 denominado assim de suboblato.

PALAVRAS-CHAVE: diâmetro polar, método colorimétrico, Sorghum bicolor 


\title{
USE OF DIFFERENT COLORS FOR THE ESTIMATION OF POLYNICAL FEASIBILITY AND CHARACTERIZATION OF GRAINS FROM GRANIFERO SORGO POLLENS
}

\begin{abstract}
Like the great majority of cultivated plants, the sorghum crop is subject to different environmental variations. Thus, the typical photoperiodic response of short days and high photosynthetic rates is related to good growth, development, and germination of pollen. The objective of this work was to estimate the pollen viability, under different types of dyes and the characterization of the pollen grain, as to its viability and size. 250 pollen / slide grains, with 30 replicates, were analyzed using a Primo Star Carl Zeiss optical microscope. The images were captured by means of a binocular photomicroscope (Leica ICC 50) coupled to a computer and to the LAZ EZ V1 software. 7.0, for the characterization of its equatorial diameter morphology (DE) and polar diameter (DP) by ImageJ software. The average of pollen viability were submitted to analysis of variance (ANOVA) in the SISVAR® software, using the Tukey test at $5 \%$ probability. The analysis of pollen grains of the hybrid BRS 330 , using three different dyes to estimate pollen viability, showed a high rate of viable pollen, above $94 \%$, with acetic orcein presenting the highest percentage of viable pollen (96.24\%), followed by Alexander (94.68\%) and finally Lugol (94.04\%). The average ratio for the polar diameter and equatorial diameter was higher for the viable polens with a value of 0.94 , thus determining the pollen classification in relation to its shape, being this oblato-spheroidal, whereas the non-pollen grains presented an average of 0.80 denominated thus of suboblate.
\end{abstract}

KEYWORDS: polar diameter, colorimetric method, Sorghum bicolor

\section{INTRODUÇÃO}

O sorgo (Sorghum bicolor L. Moench) é um grão de origem tropical, cultivado em várias regiões do mundo, sendo utilizado principalmente para alimentação animal, e, em alguns países, como fonte de alimentação humana. No Brasil, o grão de sorgo é empregado basicamente na alimentação animal, como alternativa para suprir a demanda de grãos, em complemento ao milho, possibilitando uma redução de custos, porém, conservando a qualidade nutricional (RODRIGUES, 2012).

Essa cultura é uma das alternativas de cereal para a fabricação de produtos devido à sua composição nutricional e também por ser uma fonte ainda não muito explorada na alimentação humana. Alguns estudos têm demonstrado que o sorgo é nutricionalmente tão importante quanto o milho e o trigo (Almeida Filho et al., 2014), existem diversos compostos fenólicos no grão de sorgo, sendo que eles podem afetar a cor, aparência e a qualidade nutricional (ALTHWAB et al., 2015).

A cultura do sorgo apresentou expressiva expansão nos últimos anos agrícolas, principalmente no período de safrinha, em sucessão às culturas de verão. Sendo considerado o quinto cereal mais produzido no mundo, depois do milho, trigo, arroz e cevada, com produção mundial em 2012 de 57,0 milhões de toneladas, em área de 38,2 milhões de hectares (FAO, 2014). O Centro Oeste é a principal região sorgueira, responsável por aproximadamente $60,0 \%$ da produção nacional e 50,0\% da área cultivada no Brasil (CONAB, 2014), devido a sua adaptação a uma ampla variação de ambientes e produção sob condições desfavoráveis quando comparado 
à maioria dos outros cereais. Com tolerância à seca é considerado como um cultivo mais apto para regiões áridas com chuvas escassas.

O sorgo é uma planta autógama, com baixa taxa de fecundação cruzada. Apresenta metabolismo C4, resposta fotoperiódica típica de dia curto e de altas taxas fotossintéticas. A grande maioria dos materiais genéticos comerciais de sorgo requer temperaturas superiores a $21^{\circ} \mathrm{C}$ para um bom crescimento, desenvolvimento, e germinação do pólen, pois germina imediatamente se cair num estigma receptivo e a fertilização ocorre em torno de duas horas depois, no entanto, a luz é necessária para a germinação e o pólen espalhado à noite não germina até o amanhecer. Porém, vale ressaltar que temperaturas elevadas podem reduzir a longevidade do pólen e sua germinação, devido a mudanças em sua estrutura e no conteúdo de carboidratos. O grão de sorgo igualmente varia muito quanto à cor, dureza, forma e tamanho (EMBRAPA, 2012).

Este trabalho teve por objetivo estimar a viabilidade polínica, da espécie Sorghum bicolor L. Moench, sob diferentes tipos de corantes e a caracterização do grão de pólen, quanto o tamanho.

\section{MATERIAL E MÉTODOS}

As análises citológicas foram realizadas no Laboratório de Citogenética e Laboratório Didático I da Universidade do Estado de Mato Grosso, localizada no município de Alta Floresta - MT. O material utilizado para as análises foi o híbrido de sorgo BRS 330 da Embrapa, seguindo os protocolos convencionais de citogenética descritos por Guerra e Souza (2002).

O híbrido foi coletado, aleatoriamente, com botões florais, em diferentes fases de desenvolvimento, de plantas mantidas em experimento da Embrapa em Vilhena, Rondônia. Esses foram fixados em ácido acético e estocados em refrigerador, até a análise, e lavadas em água destilada por um período de $10 \mathrm{~min}$, com duas trocas. $\mathrm{Na}$ preparação das lâminas, as anteras foram maceradas e coradas com uma 1 gota de lugol forte $2 \%$, Alexander $2 \%$ e orceína acética $2 \%$, com 10 repetições para cada tipo de coloração.

Para a viabilidade do pólen foi estimada, a partir da análise de 250 grãos de pólen/ lâmina, sendo 30 lâminas observadas, em microscópio óptico modelo Primo Star Carl Zeiss. Grãos com tamanho visivelmente normal, protoplasma corado e com a exina intacta foram considerados como viáveis e aqueles vazios e, ou mal formados, como inviáveis. A viabilidade polínica foi calculada pela seguinte fórmula:

$$
\text { Viabilidade do pólen }(\%)=\frac{\mathrm{N}^{\circ} \text { de grãos de pólen corados } \times 100}{\mathrm{~N}^{\circ} \text { de grãos pólen total }}
$$

Após confecção das lâminas foram capturadas imagens por meio de um microscópio fotômico binocular (Leica ICC 50) acoplado a um computador e no software LAZ EZ V1. 7.0, sob objetiva de 100x, com coloração safranina a 1\%, para melhor visualização das imagens.

Os grãos de pólen foram analisados quanto a sua morfologia de diâmetro equatorial (DE) e diâmetro polar (DP), pelo software ImageJ. As médias da viabilidade polínica foram submetidas à análise de variância (ANOVA), no software SISVARß (FERREIRA, 2011), pelo teste Tukey à 5\% de probabilidade. 


\section{RESULTADOS E DISCUSSÃO}

Obter informação sobre a viabilidade polínica é de interesse para trabalhos de biologia reprodutiva, ou ainda em programas de melhoramento, ajudando no estudo ecológico e taxonômico de uma espécie, ajudando nas informações para utilizar no processo de conservação genética. Um dos métodos para estudo é o teste colorimétrico (SANTOS et al., 2015).

Em relação às análises com os diferentes corantes para estimar a viabilidade polínica utilizando três diferentes corantes mostrou uma alta taxa de pólen viável, acima de $94 \%$, sendo que a orceína acética apresentou o maior percentual de pólens viáveis (96.24\%), seguido do reagente de Alexander (94.68\%) e por último o Lugol (94.04\%). Pode-se observar na Tabela 1, que nenhum corante diferiu estatisticamente, pelo teste de Tukey a $5 \%$ de probabilidade.

Diversas espécies produzem alto percentual de polens viáveis, mas alguns não são utilizados na fertilização, podem ser perdidos no transporte através dos ventos ou sendo alimentação de insetos, dessa maneira quanto maior a taxa de polens viáveis, maior a chance de fertilização (SANTOS et al., 2015).

O coeficiente de variação (CV (\%)) encontrado nas três metodologias, é um valor relativamente baixo de $2.6 \%$, que demonstra uma homogeneidade e precisão na realização da análise. Conforme Pimentel-Gomes (1985) em seu estudo fez a determinação dos valores de CV onde variam de baixos a alto, sendo que os menores de $10 \%$ são os considerados baixos, demonstrando uma alta precisão (Tabela 1).

Os três corantes foram capazes de distinguir os pólens viáveis dos inviáveis, podendo ver nitidamente a diferença entre os grãos de pólen dos mesmos, devido que os inviáveis possuem uma cor mais clara, ou por não ficarem corados por completo (Figura 1). Contudo, devido uma maior facilidade, e maior média na distinção entre grãos de pólen viáveis e inviáveis, indica-se o uso do corante Orceína Acética, para estimar a viabilidade polínica da espécie.

TABELA 1. Média da viabilidade do pólen do sorgo granífero pela coloração de três diferentes corantes.

\begin{tabular}{|c|c|}
\hline Corantes & Médias \\
\hline Lugol & $94.04 \mathrm{a}$ \\
\hline Alexander & $94.68 \mathrm{a}$ \\
\hline Orceina & $96.24 \mathrm{a}$ \\
\hline CV (\%) & 2.16 \\
\hline
\end{tabular}

Foi realizada a análise de mensuração dos grãos de pólen viáveis e inviáveis, para maiores detalhes sobre o tamanho e forma dos pólens que é encontrado no sorgo granífero, os aspectos gerais podem ser vistos na Figura 1.

Observando a imagem, na figura $1 \mathrm{~A}$, pode-se ver os polens viáveis e na figura $1 \mathrm{~B}$ os polens inviáveis, pode-se através da imagem perceber como a diferença entre 
os dois são perceptíveis, consegue-se notar que além da coloração o tamanho é diferente. E através da mensuração foi possível comprovar tais informações.
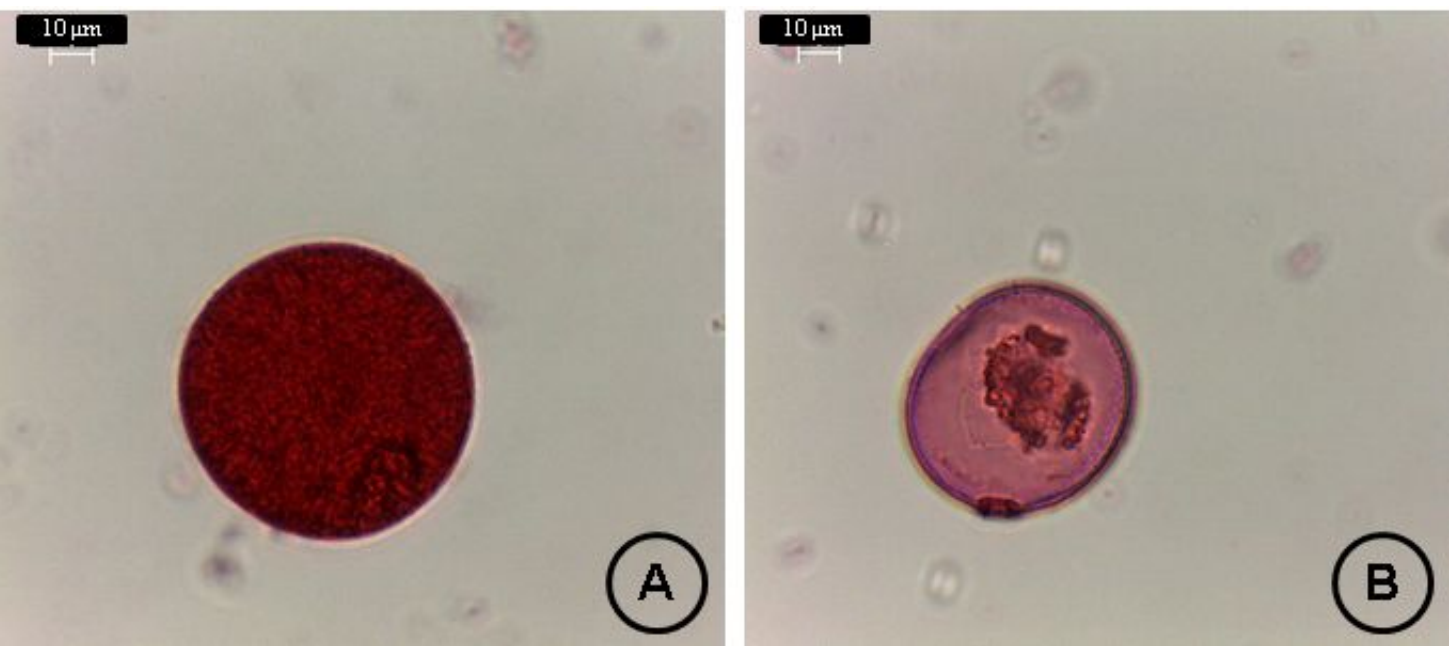

FIGURA 1: Grãos de Pólen. A) Grão de pólen viável; B) Grão de pólen inviável.

Em relação ao tamanho, os grãos de pólen foram classificados como grandes, tanto os viáveis como os inviáveis, devido a média do seu maior eixo ser de 71.26 e 62.05 respectivamente, estando no intervalo de 50-100um conforme (ERDTMAN, 1945). Porém analisando os mesmo, foram classificados da mesma maneira, mas obtiveram tamanhos diferentes, obtendo uma média menor para o diâmetro polar e equatorial os polens inviáveis.

A média para a relação diâmetro equatorial por diâmetro polar foi maior para os polens viáveis com valor de 0.94 (Tabela 2), determinando assim a classificação do pólen em relação ao seu formato, sendo este oblato-esferoidal, já os grãos de pólen inviáveis apresentou média de 0.80 denominado assim de suboblato (ERDTMAN, 1952).

TABELA 2: A média, desvio padrão e o coeficiente de variação da relação diâmetro equatorial pelo diâmetro polar dos grãos de pólen do sorgo granífero.

\begin{tabular}{ccc}
\hline & Viável & Inviável \\
\hline Média & 0.94 & 0.80 \\
Desvio padrão & 0.07 & 0.13 \\
\hline CV(\%) & $\mathbf{8 . 1 2}$ & $\mathbf{1 6 . 1 8}$ \\
\hline
\end{tabular}

Com um coeficiente de variação baixo devido os valores serem 8 e 16\% (Tabela 2), mostra-se que a análise foi realizada com precisão, que a utilização do software para mensuração dos grãos de pólen foi de suma importância para obtenção dos dados. Na literatura não há estudos em relação aos grãos de pólen de sorgo granífero, tornando-se este estudo de grande importância, além de contribuir mais para realização de outros trabalhos, em relação a esta espécie. 


\section{CONCLUSÃO}

Os corantes Alexander, Orceína Acética e Lugol foram capazes de distinguir com segurança os pólens do sorgo granífero viáveis dos inviáveis, sendo que o genótipo utilizado apresenta uma taxa alta de viabilidade polínica, independente do corante. A Orceína Acética $2 \%$ apresentou a maior média para os resultados de viabilidade polínica.

Em relação ao diâmetro dos pólens, mostrou diferença quanto a classificação, associado ao tamanho e formas irregulares dos pólens inviáveis.

\section{REFERÊNCIAS}

ALMEIDA FILHO, J. E.; TARDIN, F.D.; DAHER, R.F.; SILVA, K.J.; XAVIER NETO, J.B.; BASTOS, E.; LOPES, V.S.; BARBÉ, T.C.; MENEZES, C.B. Avaliação agronômica de híbridos de sorgo granífero em diferentes regiões produtoras do Brasil. Revista Brasileira de Milho e Sorgo, v.13, n.1, p.82-95, 2014. DOI: http://dx.doi.org/10.18512/1980-6477/rbms.v13n1p82-95.

ALTHWAB, S.; CARR, T.P.; WELLER, C.L.; DWEIKAT, I.M.; SCHLEGEL, V. Advances in grain sorghum and its co-products as a human health promotion dietary system. Food Research International, v. 77, p. 349-359, 2015. Disponível em: < https://www.sciencedirect.com/science/article/pii/S0963996915301472>. DOI: http://dx.doi.org/10.1016/j.foodres.2015.08.011

COMPANHIA NACIONAL DE ABASTECIMENTO. Acompanhamento de safra brasileira: grãos, levantamento, setembro, 2014. Brasília: Conab, 2014. 40p.

EMBRAPA. Embrapa Milho e Sorgo. Cultivo do sorgo. Sistema de Produção, 2, 8 edição, 2012. Disponível em: https://www.embrapa.br/milho-e-sorgo/. Acesso em: 19/10/2017.

ERDTMAN G. Pollen morphology and plant taxonomy Angiosperms. Stockholm Alqmvist and wiksell, 541p, 1952.

ERDTMAN G. Pollen morphology and plant taxonomy. III. Morina L. with an addition on pollen morphological terminology. Svenskbo. Tidsrk. 527p, 1945.

FAO. Food and Agriculture Organization of the United Nations. 2014. Disponível em: www.fao.org/. Acesso em 17/10/2017.

FERREIRA, D. F. Sisvar: a computer statistical analysis system. Ciência \& Agrotecnologia, v. $35, \quad$ n. $6, \quad$ p.1039-1042, $2011 . \quad$ DOI: http://dx.doi.org/10.1590/S1413-70542011000600001.

GUERRA, M.; SOUZA, M. J. Como observar cromossomos. Ribeirão Preto: Ed. Funpec, 2002, 131p.

PIMENTEL GOMES, F. Curso de Estatística Experimental. São Paulo: Nobel, 1985. $467 \mathrm{p}$.

RODRIGUES J.A.S. Cultivo do sorgo. Embrapa Milho e Sorgo. Sete Lagoas, 8 ed., 2012. 
SANTOS, T. A dos; TIAGO, P. V.; SCHMITT, K. F. M.; MARTINS, K. C.; ROSSI, A. A. B. Viabilidade polínica em Bertholletia excelsa Bonpl. (Lecythidaceae) baseada em diferentes testes colorimétricos. Enciclopédia Biosfera, Centro científico conhecer- Goiânia-GO, v. 11 n.22, 2015.

DOI: http://dx.doi.org/10.18677/Enciclopedia_Biosfera_2015_030. 